This composition of two repeated hierarchies (stacks and bundles) provides great strength - the ability to withstand mechanical pressure without giving way-and at the same time great robustness - the ability to perform mechanically,

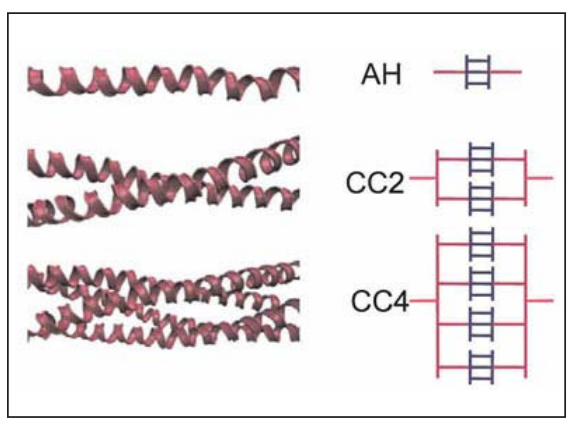

Figure 1. Illustration of different arrangements of alpha-helical protein filaments and their schematic representation in their model. (Image: Prof. Markus

Buehler, MIT) even if faults are present, the researchers said. Alpha-helices are a common protein building block of cellular filaments, hair and hoof, stabilized through weak intramolecular hydrogen bonds.

As reported in the February 18 issue of Nanotechnology (DOI: 10.1088/0957$4484 / 20 / 7 / 075103)$, the researchers used modeling based on molecular dynamics simulations to test the strength and robustness of four different combinations of eight alpha-helical proteins: a single stack of eight proteins, two stacks of four bundled proteins, four stacks of two bundled proteins, and double stacks of twobundled proteins. Their molecular models replicate realistic molecular behavior, including hydrogen bond formation in the coiled springlike alpha-helical proteins (see Figure 1).

In a follow-up study that will appear in the inaugural issue of the International Journal of Applied Mechanics, Buehler and his graduate students Zhao Qin and Steve Cranford ran similar tests using more than 16,000 elements instead of eight. The most successful of those again utilized the bundles of four alpha-helical proteins. That analysis shows that random arrangements of elements typically led to inferior performance, and may explain why many engineered materials are not yet capable of combining disparate properties such as robustness and strength. Only a few specific nanostructured arrangements provide the basis for optimal materials performance, and this must be incorporated in the materials design process, the research team said.

"The traditional way of designing materials is to consider properties at the macro level, but a more efficient way of materials' design is to play with the structural makeup at the nanoscale," said Buehler, the Esther and Harold E. Assistant Professor in the Department of Civil and Environmental Engineering. "This provides a new paradigm in engineering that enables us to design a new class of materials."

DENISE BREHM (Sr. Communications Officer, MIT)

\section{Nuclear Fusion-Fission Hybrid Designed to Destroy Nuclear Waste}

Researchers at The University of Texas at Austin have designed a fusion-fission hybrid system that, when fully developed, would use fusion to burn most of the transuranic waste produced by nuclear power plants. Furthermore, the system would produce energy during the process. The invention would reduce nuclear waste, making nuclear energy more broadly acceptable and thus could be used to help combat global warming.

"We have created a way to use fusion to relatively inexpensively destroy the waste from nuclear fission," said Mike Kotschenreuther with the Institute for Fusion Studies (IFS) and Department of Physics. "Our waste destruction system, we believe, will allow nuclear powera low carbon source of energy-to take its place in helping us combat global warming."

As reported in the January issue of Fusion Engineering and Design (DOI: 10.1016/j.fusengdes.2008.11.019; p. 83), Kotschenreuther, Swadesh Mahajan, and Prashant Valanju of the IFS, and E.A. Schneider of the Department of Mechanical Engineering at the University of Texas at Austin propose destroying the waste using a fusion-fission hybrid reactor, the centerpiece of which is a high-power compact fusion neutron source (CFNS) made possible by their invention of the Super- $X$
Divertor - a redesign of the magnetic geometry at the plasma edge that enables safe handling of the enormous heat and neutron fluxes in CFNS-(see Figure 1).

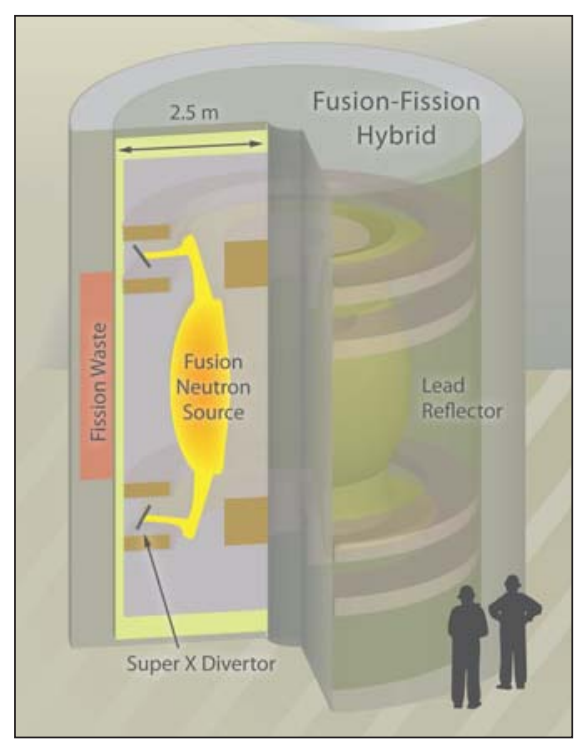

Figure 1. The compact fusion neutron source (CFNS) drives the fusion-fission hybrid. The hybrid burns long-lived waste using abundant neutrons from the CFNS. The Super-X Divertor makes it possible to handle the enormous heat produced by the CFNS. (Credit: Angela P. Wong, The University of Texas at Austin)
"The intense heat generated in a nuclear fusion device can literally destroy the walls of the machine," said Valanju, "and that is the thing that has been holding back a highly compact source of nuclear fusion."

The CFNS would provide abundant neutrons through fusion to a surrounding fission blanket that uses transuranic waste as nuclear fuel. The fusion-produced neutrons augment the fission reaction, imparting efficiency and stability to the waste incineration process.

The researchers' waste destruction system would work in two major steps.

First, $75 \%$ of the original reactor waste is destroyed in standard, relatively inexpensive light water reactors (LWRs). This step produces energy, but it does not destroy highly radiotoxic, transuranic, long-lived waste, what the researchers call "sludge."

In the second step, the sludge would be destroyed in a CFNS-based fusion-fission hybrid. The hybrid's potential lies in its ability to burn this hazardous sludge, which cannot be stably burnt in conventional systems.

One hybrid would be needed to destroy the waste produced by 10 to 15 LWRs. The process would ultimately reduce the transuranic waste from the original fission reactors by up to $99 \%$. Burning that waste also produces energy. Much fewer of the devices would be needed compared to 
other schemes that are being investigated for similar processes. In combination with the substantial decrease in the need for geological storage, the CFNS-enabled waste-destruction system would be much cheaper and faster than other routes, the researchers said.

"It's always been known that fusion is good at producing neutrons and fission is good at making energy," Valanju said. "Now, we have shown that we can get fusion to produce a lot of neutrons in a small space."

Producing an abundant and clean source of "pure fusion energy" continues to be a goal for fusion researchers. But the researchers said that harnessing the other product of fusion-neutrons-can be achieved in the near term.

"The hybrid we designed should be viewed as a bridge technology," said Mahajan. "Through the hybrid, we can bring fusion via neutrons to the service of the energy sector today. We can hopefully make a major contribution to the carbonfree mix dictated by the 2050 time scale" set by scientists of global warming.

Next steps will include performing extended simulations, transforming the concept into an engineering project, and seeking funding for building a prototype.

\section{News of MRS Members/Materials Researchers}

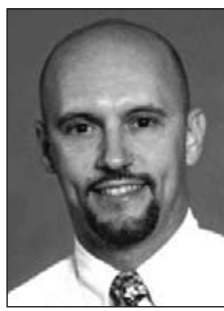

Alexander E. Farrell
Alexander E. Farrell, associate professor at the University of California, Berkeley, died in April 2008. Alex came to the Energy and Resources Group at UCBerkeley after managing the ElectricityIndustry Center at Carnegie Mellon University - a research and outreach center focused both on innovation and genuine academia-industry partnership in the energy field. Prior to that, Alex had been a postdoctoral fellow in the Science and Technology Policy program at the J.F. Kennedy School at Harvard University, and did his doctoral work on energy at the University of Pennsylvania. Prior to that, Alex served in the nuclear submarine fleet in the U.S. Navy, after receiving his undergraduate education at the U.S. Naval Academy. All of these periods of time, and experiences, were very much apparent in, and part of, who Alex was as a person.

Alex continued to collaborate withand remained close friends and business partners with-several of the postdoctoral fellows from his time at Harvard. Similarly, the collaborations and friendships from Alex's time at Carnegie Mellon were some of the closest bonds I have ever seen between professional colleagues. Alex lived and breathed the science and technology policy methods, approaches, and, in fact, the overall ethos of the CMU community.

From day one of his time at Berkeley, Alex focused on transportation issues, and very rapidly became a key player in the state, regional, and international discussions on a wide range of transportation and energy issues. His projects extended over assessments of the energy and climate impacts of biofuels-(e.g., Farrell, Plevin, Turner, Jones, O'Hare, and Kammen, Science 311 2006) - a paper that became a "cottage industry" in itself, with thousands of academic and media requests, and a remarkable team of students including Rich Plevin, Andy Jones, Brian Turner, and others, who have continued in the Alex tradition of careful and detailed analytical assessment of fuels.

At the same time, Alex and his doctoral student Adam Brandt were developing an assessment of the environmental impacts of unconventional forms of oilthose derived from tar sands, shale rock, and other sources-many of which come with a far larger "environmental footprint" than does gasoline (Farrell and Brandt, 2006). Their subsequent article became a "best seller" in a new journal, Environmental Research Letters, which is notable for the open access format that Alex favored. The Farrell and Brandt paper appeared in the inaugural issue. In fact, Alex has been the most frequent contributor to Environmental Research Letters.
These efforts led to a defining project in Alex's career-collaboration, analysis, and education and collaboration with industry, elected officials, and the nongovernmental sector efforts around the design of a low carbon fuel standard (LCFS). The LCFS sets a fleet-wide maximum greenhouse gas impact for transportation-measured on a life-cycle basis-and has been globally influential in re-thinking how we assess and regulate vehicle pollution. The project was vetted frequently during the process of developing the two major reports with individuals from industry, government agencies, and colleagues in Europe who where working on various national and European Union commissions.

Governor Schwarzenegger signed Executive Order S-1-07 enacting the LCFS in January 2007.

For the Materials Research Society, Alex contributed to the MRS Bulletin special issue on materials and energy (April 2008); his article on bioenergy research needs, co-authored with Anand Gopal, remains highly cited.

Throughout his career, Alex continued to expand the range of technologies and practices he studied. The day he died, Alex was working on a detailed assessment of battery issues for work on plug-in hybrid vehicles (Lemoine, Farrell and Kammen, Environ. Res. Lett. 3 2008).

DANIEL M. KAMMEN

\footnotetext{
Correction

In the March 2009 issue of MRS Bulletin 34 (3) (2009) p. 182, reference 90 was omitted: "The MD simulations further found that these wires exhibit both novel shape memory and pseudoelastic behavior under tensile loading $78-82,90$ that is not seen in the corresponding bulk material." Reference 90: H.S. Park, K. Gall, J.A. Zimmerman, Phys. Rev. Lett. 95 255504 (2005)
}

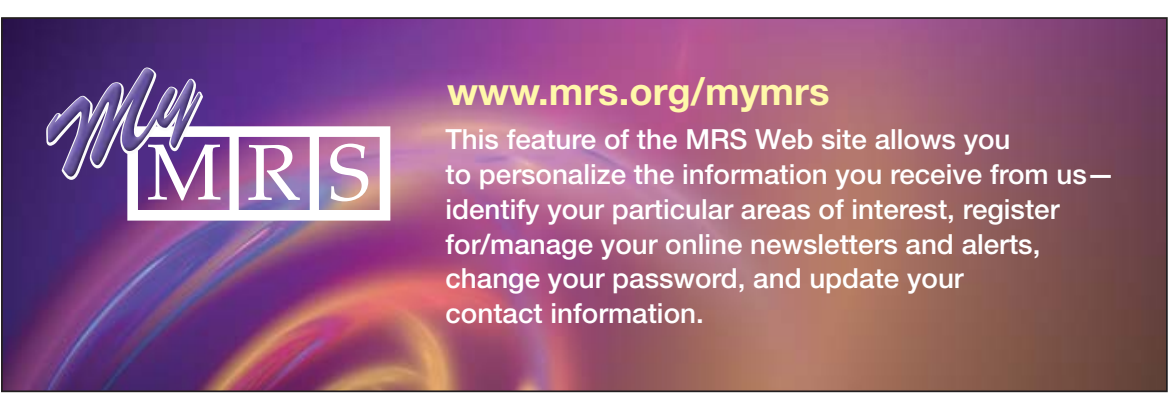

